ARTICLE

https://doi.org/10.1038/s41467-018-07711-y

\title{
Lithium hexamethyldisilazide initiated superfast ring opening polymerization of alpha-amino acid $\mathrm{N}$-carboxyanhydrides
}

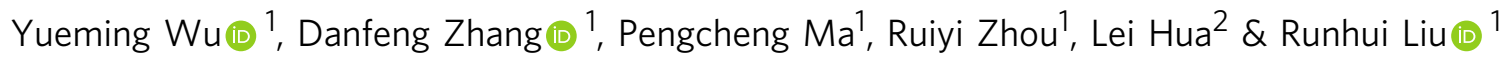

Polypeptides have broad applications and can be prepared via ring-opening polymerization of $\alpha$-amino acid $N$-carboxyanhydrides (NCAs). Conventional initiators, such as primary amines, give slow NCA polymerization, which requires multiple days to reach completion and can result in substantial side reactions, especially for very reactive NCAs. Moreover, current NCA polymerizations are very sensitive to moisture and must typically be conducted in a glove box. Here we show that lithium hexamethyldisilazide (LiHMDS) initiates an extremely rapid NCA polymerization process that is completed within minutes or hours and can be conducted in an open vessel. Polypeptides with variable chain length ( $D P=20-1294)$ and narrow molecular weight distribution $(\mathrm{Mw} / \mathrm{Mn}=1.08-1.28)$ were readily prepared with this approach. Mechanistic studies support an anionic ring opening polymerization mechanism. This living NCA polymerization method allowed rapid synthesis of polypeptide libraries for high-throughput functional screening.

\footnotetext{
${ }^{1}$ State Key Laboratory of Bioreactor Engineering, Key Laboratory for Ultrafine Materials of Ministry of Education, Research Center for Biomedical Materials of Ministry of Education, School of Materials Science and Engineering, East China University of Science and Technology, 200237 Shanghai, China. ${ }^{2}$ Research Center of Analysis and Test, East China University of Science and Technology, 200237 Shanghai, China. Correspondence and requests for materials should be addressed to R.L. (email: rliu@ecust.edu.cn)
} 
S ynthetic polypeptides are biocompatible and have a broad range of applications including protein/peptide mimicking $^{1-4}$, antimicrobial agents and materials ${ }^{5-14}$, drug, and gene delivery ${ }^{15-18}$, tissue engineering and other biomaterial applications ${ }^{19-25}$. Polypeptides can be synthesized from the polymerization of $\alpha$-amino acid $N$-carboxyanhydride (NCA), the Leuchs' anhydride discovered in 1906 by Hermann Leuchs ${ }^{26-28}$. Since that time, alcohols, amines and related compounds have been used to initiate NCA polymerization; primary amines have been the most common initiators ${ }^{29-32}$. In recent years, continues studies on NCA polymerization were reported by using transition metal complexes ${ }^{33-35}$, hexamethyldisilazane and trimethylsilyl derivatives $^{36-38}$, Al-Schiff base complexes ${ }^{39}$, rare earth metal complexes $^{40}$, ammonium salts ${ }^{41-43}$, and amine-borane Lewis pairs as the initiator ${ }^{44}$. Other efforts have included the use of a thiourea organocatalyst ${ }^{45}$, and the exploration of modified reaction conditions such as low temperature ${ }^{46,47}$, high vacuum ${ }^{48-50}$, and nitrogen flow ${ }^{51}$. Despite these innovations, NCA polymerization is still challenging due to its high sensitive to moisture and generally need to operate in a glove box.

We report the discovery that lithium hexamethyldisilazide (LiHMDS) initiates very rapid ring-opening NCA polymerization to generate polypeptides with low dispersity, over a wide range of average chain length. We show that LiHMDS-initiated NCA polymerization can be conducted on the benchtop, in an open vessel, which facilitates parallel synthesis (for library generation) and large-scale synthesis of specific materials. The merits of our method are illustrated via the preparation and screening of polypeptide libraries for antibacterial activity. We identify potent and broad-spectrum polymers that target antibiotic-resistant strains of Pseudomonas aeruginosa $(P$. aeruginosa) and methicillin-resistant Staphylococcus aureus (MRSA).

\section{Results}

Reaction rates of NCA polymerization initiated by different initiators. LiHMDS has previously been used to initiate the anionic ring-opening polymerization of $\beta$-lactams to afford nylon-3 polymers that display a variety of biological applications ${ }^{19,52-59}$. We therefore wondered whether LiHMDS would be effective in deprotonating $\mathrm{NH}$ in the NCA ring and initiate NCA polymerization (Fig. 1a). Two widely-used NCAs were employed, those derived from $\gamma$-benzyl-L-glutamate NCA (BLG NCA) and from Ne-tert-butyloxycarbonyl-D,L-lysine NCA (Boc-D,L-Lys NCA) (see NCA synthesis details in Supplementary Methods and Supplementary Figs. 8-22), so that we could compare our findings to those of others. Many previous studies have employed DMF or THF as the solvent for NCA polymerization; our preliminary studies revealed that THF is superior because the NCAs are more stable in this solvent than in DMF to minimize side reactions possibly associated with impurities in solvents such as water and chloride ions (see NCA stability studies in Supplementary Discussion and Supplementary Fig. 1) ${ }^{60-62}$.

Surprisingly, we observed that LiHMDS causes superfast polymerization of each NCA. For reactions involving 20:1 NCA:LiHMDS, both BLG NCA and Boc-D,L-Lys NCA were consumed very quickly, and the reactions were complete within $10 \mathrm{~min}$ and $15 \mathrm{~min}$, respectively (Fig. 1). For reactions involving 100:1 or 500:1 NCA:LiHMDS, BLG NCA was consumed within $2 \mathrm{~h}$, whereas Boc-D,L-Lys NCA required 7 or $21 \mathrm{~h}$ for complete consumption. We used the results summarized above as a basis for comparing our method with NCA polymerization methods described previously. Hexylamine, hexamethyldisilazane and bipyNi(COD) (Supplementary Table 1 and Supplementary Fig. 23 for NMR) were employed for these comparisons. With both hexylamine and hexamethyldisilazane, very little polymerization was detected at any of the time points we monitored for either NCA starting material (Fig. 1). Excellent work by Deming et al. has established that bipyNi(COD) is an effective catalyst for NCA polymerization $^{34}$, and our observations reinforce the advantages of the Ni-catalyzed process relative to polymerizations initiated with an amine. However, our data clearly establish the superiority of LiHMDS-initiated polymerizations, particularly those conducted with high NCA:initiator ratios (i.e., for synthesis of polymers with high molecular weight).

Synthesis and characterization of poly-BLG and poly-Boc-D,LLys. Above observation on LiHMDS-initiated superfast NCA polymerization encouraged us to further explore this attractive strategy for polypeptide synthesis, with our focus on two popular NCA monomers: BLG NCA and Boc-D,L-Lys NCA. LiHMDS
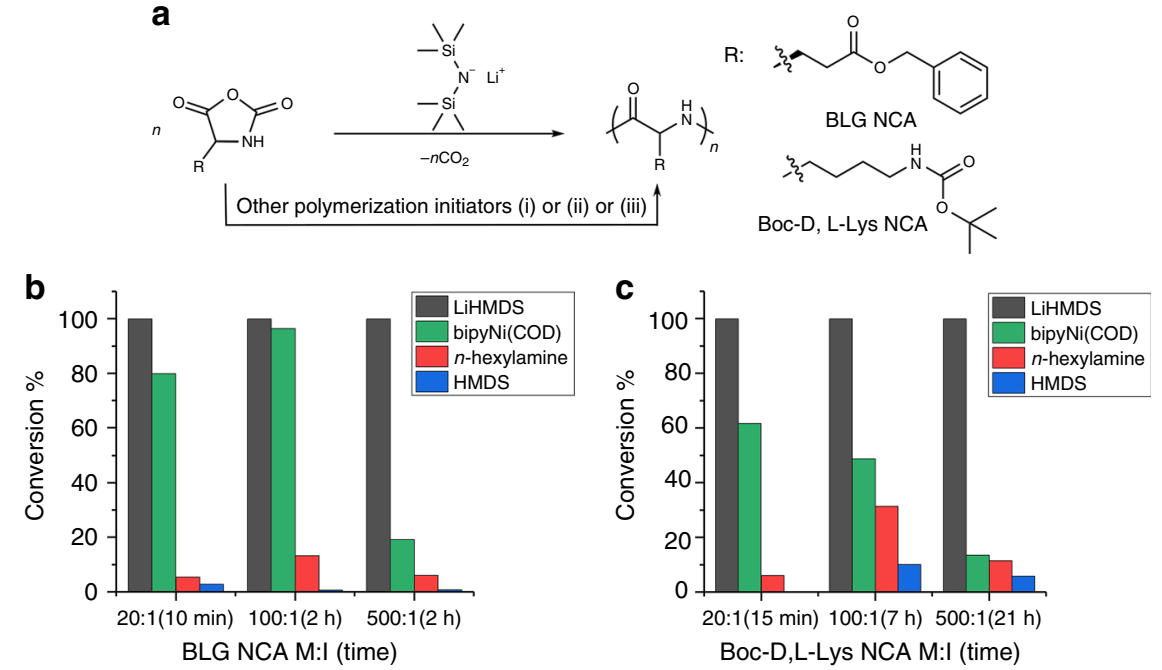

Fig. 1 Ring-opening polymerization of NCA initiated by LiHMDS and other initiators. a NCA polymerization initiated by LiHMDS or other initiators in THF, initiator (i) n-hexylamine, initiator (ii) HMDS, initiator (iii) bipyNi(COD); b conversion of BLG NCA in LiHMDS, n-hexylamine, HMDS or bipyNi(COD) initiated polymerization at variable NCA:initiator ratios using THF as the reaction solvent; c conversion of Boc-D,L-Lys NCA in LiHMDS, n-hexylamine, HMDS, or bipyNi(COD) initiated polymerization at variable NCA:initiator ratios using THF as the reaction solvent 


\begin{tabular}{|c|c|c|c|c|c|}
\hline Entry & Initiator & M:I & $\begin{array}{l}\mathrm{Mn} \\
\left(\mathrm{g} \mathrm{mol}^{-1}\right)\end{array}$ & Đ & DP \\
\hline 1 & LiHMDS & 5 & 7490 & 1.23 & 34 \\
\hline 2 & LiHMDS & 10 & 16,260 & 1.25 & 74 \\
\hline 3 & LiHMDS & 20 & 27,340 & 1.20 & 124 \\
\hline 4 & LiHMDS & 100 & 78,090 & 1.24 & 357 \\
\hline 5 & LiHMDS & 500 & 111,900 & 1.15 & 510 \\
\hline $6^{a}$ & n-hexylamine & 20 & 4580 & 1.04 & 21 \\
\hline 7 & n-hexylamine & 100 & 27,970 & 1.23 & 127 \\
\hline $8^{\mathrm{b}}$ & n-hexylamine & 500 & 60,770 & 1.26 & 277 \\
\hline 9 & HMDS & 20 & 7470 & 1.01 & 34 \\
\hline 10 & HMDS & 100 & 32,070 & 1.22 & 146 \\
\hline $11^{b}$ & HMDS & 500 & 56,120 & 1.36 & 256 \\
\hline 12 & bipyNi(COD) & 20 & 23,800 & 1.28 & 108 \\
\hline 13 & bipyNi(COD) & 100 & 123,100 & 1.29 & 562 \\
\hline 14 & bipyNi(COD) & 500 & 458,100 & 1.16 & 2091 \\
\hline
\end{tabular}

Note: Polymerization of BLG NCA using LiHMDS as the initiator (entry 1-5) was compared to polymerization using $\mathrm{n}$-hexylamine (entry 6-8), HMDS (entry 9-11), or bipyNi(COD) (entry 12-14) as the initiator. All polymers were synthesized using THF as the solvent and were characterized by GPC using DMF as the mobile phase. Mn is the obtained number average molecular weight, $\boxminus$ is the dispersity index, DP is the obtained degree of polymerization molecular weight, $€$ is the dispersity index, DP is the obtained degree of polymerization
a a bimodal GPC trace was obtained with unexpected high Mn component (Fig. $2 \mathrm{~d}$ for bimoda GPC trace)

significant amount of NCA was left even after the polymerization reaction continued for 5 days

can initiate successful polymerization of BLG NCA to provided poly-BLG with narrow dispersities $(\mathrm{D}=1.15-1.25)$ and variable chain lengths ( $\mathrm{DP}=34-510$ ) (Table 1, entry 1-5; Fig. 2a for GPC traces). We also examined polymerization of BLG NCA using LiHMDS from different sources, different lots and different synthetic methods ${ }^{63}$. All six LiHMDS samples gave similar results in generating 350 mer poly-BLG (Supplementary Fig. 2, full scale GPC in Supplementary Figs. 90-95). Both n-hexylamine and HMDS were able to initiate controlled polymerization of BLG NCA and afford poly-BLG with short to moderate chain lengths (below 150-mer) and with narrow dispersities, although both reactions were slow, requiring 2-3 days for completion (Table 1 , entry $6-7,9-10)$. However, attempts to prepare $500-$ mer polyBLG failed with either n-hexylamine or HMDS as initiator demonstrated that after 5 days, these reactions provided materials with average chain length $<280$-mer, and a large amount of NCA remained (Table 1 , entry 8,11 ). The transition metal catalyst bipyNi(COD) can initiate BLG NCA polymerization to prepare poly-BLG with medium to long chain lengths and narrow dispersities (Table 1, entry 12-14).

LiHMDS initiated the superfast polymerization of Boc-D,L-Lys NCA and provided polypeptides with variable average lengths, ranging from 19-mer to 405-mer, and narrow dispersities (Table 2, entry 1-5; Fig. 2b for GPC traces). N-hexylamineand HMDS-initiated polymerizations of Boc-D,L-Lys NCA were much slower, paralleling the behavior noted above for BLG NCA. Yields and dispersities were good for shorter chain lengths; however, attempts to prepare 500-mer poly-Boc-D,L-Lys using nhexylamine or HMDS were unsuccessful, as was the attempt with bipyNi(COD).

Conformation analysis of poly-BLG. To answer whether LiHMDS-initiated NCA polymerization can provide polypeptides with defined secondary structures, we studied the polymerization of BLG NCA as an example ${ }^{64}$. The solutions of poly-BLG at variable chain length $(\mathrm{DP}=34,74,124)$ in hexafluoroisopropanol all displayed a positive band at $195 \mathrm{~nm}$ and two strong negative bands at $208 \mathrm{~nm}$ and $220 \mathrm{~nm}$ in circular dichroism (CD) spectra (see details in Supplementary Methods), which indicates the secondary structure of $\alpha$-helix (Fig. 2c). We also measured the specific rotations of deprotected poly-BLG $\left({ }^{1} \mathrm{H}\right.$ NMR in Supplementary Fig. 24) by polarimetry to examine the possible backbone racemization during polymerization of $\mathrm{BLG} \mathrm{NCA}^{43}$. We measured three batches of deprotected poly-BLG at $\mathrm{pH} 8.0$ and obtained specific rotation values in the range of -78 to -83 $\mathrm{deg} \cdot \mathrm{dm}^{-1} \cdot \mathrm{g}^{-1} \cdot \mathrm{mL}$ that matches the reported specific rotation at $\mathrm{pH} 8.0$ (around $-80 \mathrm{deg} \cdot \mathrm{dm}^{-1} \cdot \mathrm{g}^{-1} \cdot \mathrm{mL}$ ) in literature ${ }^{65}$. An extra study indicated a linear relationship between the specific rotation (in a range of $0-80 \mathrm{deg} \cdot \mathrm{dm}^{-1} \cdot \mathrm{g}^{-1} \cdot \mathrm{mL}$ ) and the degree of backbone racemization (Supplementary Fig. 6). Therefore, backbone racemization is not a concern during LiHMDS-initiated NCA polymerization, though we can not totally rule out this possibility. This conclusion is also consistent with that drawn from CD analysis aforementioned. It is worth mentioning that use of hexylamine as the initiator to prepare 20-mer polymer from BLG NCA or Boc-D,L-Lys, led to materials that displayed puzzling bimodal GPC traces (Fig. 2d, e). Comparable observations have been reported by other groups in reactions initiated with primary amines $^{37,66,67}$. Neither LiHMDS- nor HMDS-initiated polymerizations of BLG NCA and Boc-D,L-Lys NCA produced samples with bimodal GPC traces. The bimodal GPC data for $\mathrm{n}$ hexylamine-initiated polymerization of NCA were likely not the effect of secondary structures of resulting polypeptides because we used the Boc-D,L-Lys NCA, a racemic mixture rather than a homochirial NCA. Polypeptides prepared from the racemic BocD,L-Lys NCA are unlikely to have secondary structures like $\alpha$ helix and $\beta$-sheet.

Kinetics analysis. We studied the kinetics of LiHMDS-initiated polymerization for BLG NCA, Boc-D,L-Lys NCA and Boc-L-Lys NCA. The rate of polymerization, $k_{\mathrm{p}}[\mathrm{I}]$, was calculated from a linear fitting of the plot that depicts natural logarithm of monomer concentration change vs. reaction time. BLG NCA polymerization initiated by LiHMDS, n-hexylamine or bipyNi (COD) in THF had $k_{\mathrm{p}}[\mathrm{I}]$ values of $1.69 \mathrm{~h}^{-1}$ (Fig. $2 \mathrm{f}$ ), $0.07 \mathrm{~h}^{-1}$ or $0.87 \mathrm{~h}^{-1}$, respectively (Supplementary Fig. 5). LiHMDS-initiated polymerization of Boc-D,L-Lys NCA or Boc-L-Lys NCA in THF had $k_{\mathrm{p}}[\mathrm{I}]$ values of $0.33 \mathrm{~h}^{-1}$ or $1.57 \mathrm{~h}^{-1}$, respectively (Fig. 2f). Thus, the homochiral starting materials, BLG NCA and Boc-LLys NCA, displayed comparable reactivity, but the racemic NCA reacted more slowly.

LiHMDS-initiated open vessel NCA polymerization. Continuous studies demonstrated that LiHMDS-initiated open vessel NCA polymerization is compatible with common NCA monomers such as Boc-L-Lys NCA, N $\delta$-tert-butyloxycarbonyl-L-ornithine (Boc-L-Orn) NCA, O-(tert-butyl)-L-serine ( $t \mathrm{Bu}-\mathrm{L}-\mathrm{Ser})$ NCA, L-Leucine (L-Leu) NCA, and $\beta$-tert-butyl-L-aspartate $(t \mathrm{Bu}$ L-Asp) NCA. Homo-polymerization of these NCAs provided poly-BLG, poly-Boc-L-Lys, and poly-Boc-L-Orn with narrow dispersities $(Ð=1.08-1.28)$ and variable chain lengths (Table 3, entry 1-11; Fig. 3b-d for GPC traces). The highest number average molecular weight $(\mathrm{Mn})$ obtained from GPC characterization on poly-BLG and poly-Boc-L-Lys was $283,400 \mathrm{~g} \mathrm{~mol}^{-1}$ and $111,000 \mathrm{~g} \mathrm{~mol}^{-1}$, respectively. We also demonstrated successful NCA co-polymerization using LiHMDS as the initiator in open vessels. Polymerization on 1:1 mixture of two NCA monomers, (Boc-L-Lys NCA $+t$ Bu-L-Ser NCA), (Boc-L-Orn $\mathrm{NCA}+\mathrm{L}-\mathrm{Leu} \mathrm{NCA}$ ) and (BLG NCA $+t \mathrm{Bu}-\mathrm{L}-\mathrm{Asp} \mathrm{NCA})$, provided corresponding random co-polymers with narrow dispersities (Table 3, entry 12-14, Fig. 3e for GPC traces). Moreover, LiHMDS-initiated open vessel NCA polymerization is capable to prepare block co-polymers as demonstrated using Boc-L-Lys 

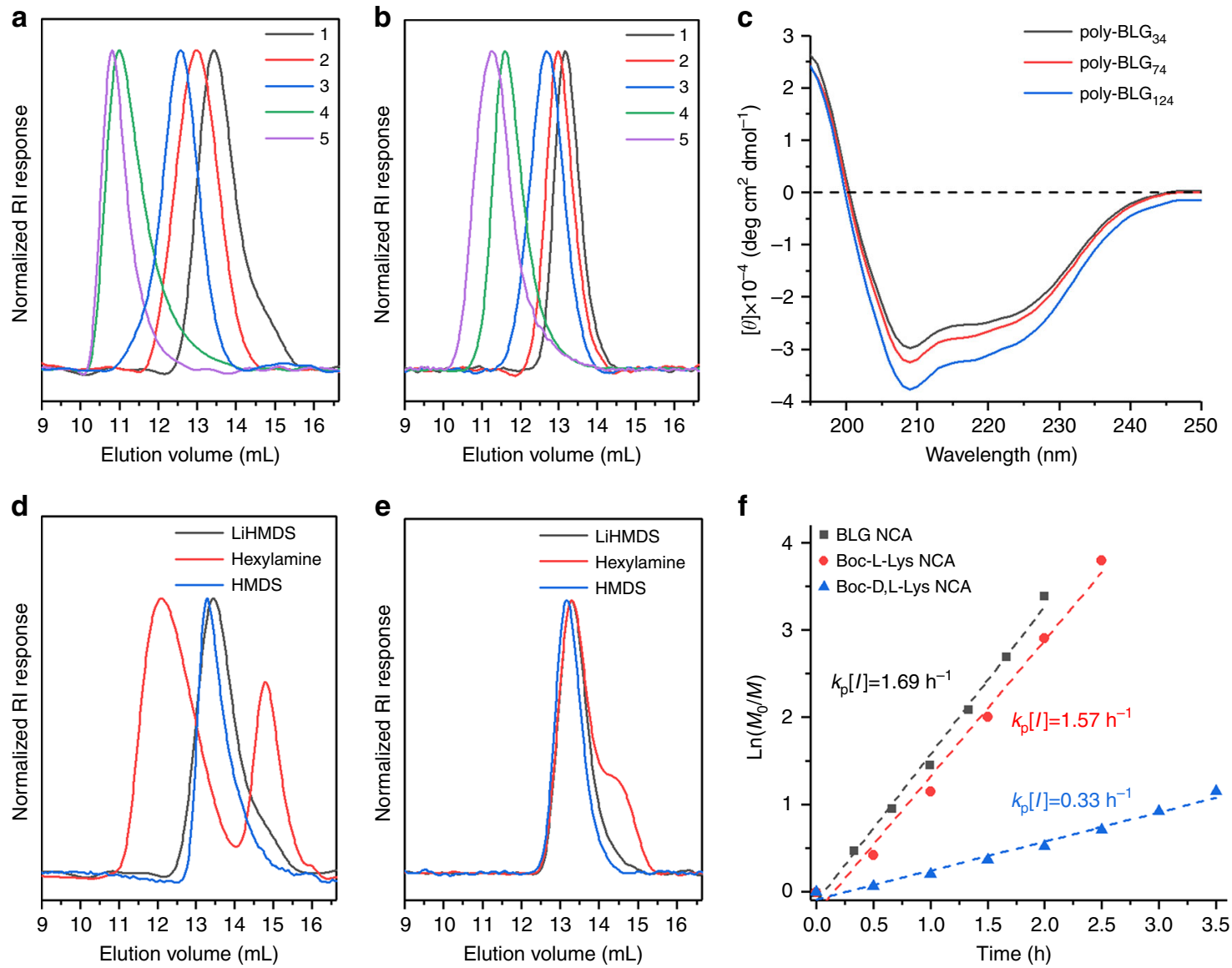

Fig. 2 Characterization of polypeptides synthesized from LiHMDS-initiated NCA polymerization. a GPC traces of poly-BLG corresponding to entry 1-5 in Table 1; b GPC traces of poly-Boc-D,L-Lys corresponding to entry 1-5 in Table 2; c CD spectra of poly-BLG at variable DP prepared from LiHMDS-initiated NCA polymerization; $\mathbf{d}$ single peak GPC traces and bimodal GPC trace obtained from LiHMDS, HMDS and n-hexylamine initiated BLG NCA polymerization, respectively; e single peak GPC traces and bimodal GPC trace obtained from LiHMDS, HMDS and n-hexylamine initiated Boc-D,L-Lys NCA polymerization, respectively; $\mathbf{f}$ reaction rates of LiHMDS initiated BLG NCA, Boc-L-Lys NCA and Boc-D,L-Lys NCA polymerization in THF with NCA:initiator ratio of 100:1 and initial NCA concentration at $0.2 \mathrm{M} ; k_{\mathrm{p}}[\mathrm{I}]$ represents the rate of polymerization reaction, whereas $k_{\mathrm{p}}$ is the rate constant of the polymerization and [I] is the concentration of initiator. All full scale GPC traces were included in the Supplementary Figs. 45-72

\section{Table 2 Characterization of poly-Boc-D,L-Lys prepared using different initiators}

\begin{tabular}{llllll} 
Entry & Initiator & M:I & $\begin{array}{l}\text { Mn } \\
\left(\mathbf{g} \mathbf{~ m o l}^{-\mathbf{1}} \mathbf{)}\right.\end{array}$ & D & DP \\
\hline 1 & LiHMDS & 5 & 4230 & 1.19 & 19 \\
2 & LiHMDS & 10 & 7250 & 1.16 & 32 \\
3 & LiHMDS & 20 & 12,370 & 1.23 & 54 \\
4 & LiHMDS & 100 & 36,300 & 1.23 & 159 \\
5 & LiHMDS & 500 & 92,340 & 1.26 & 405 \\
$6^{\text {a }}$ & n-hexylamine & 20 & 5980 & 1.35 & 26 \\
$7^{b}$ & n-hexylamine & 100 & 15,800 & 1.23 & 69 \\
$8^{\mathrm{b}}$ & n-hexylamine & 500 & 17,030 & 1.14 & 75 \\
9 & HMDS & 20 & 4250 & 1.10 & 18 \\
10 & HMDS & 100 & 16,630 & 1.25 & 73 \\
$11^{\mathrm{b}}$ & HMDS & 500 & 18,140 & 1.10 & 80 \\
12 & bipyNi(COD) & 20 & 14,600 & 1.25 & 64 \\
13 & bipyNi(COD) & 100 & 17,170 & 1.20 & 75 \\
$14^{\mathrm{b}}$ & bipyNi(COD) & 500 & 5790 & 1.20 & 25 \\
\hline
\end{tabular}

Note: Polymerization of Boc-D,L-Lys NCA using LiHMDS as the initiator (entry 1-5) was compared to polymerization using n-hexylamine (entry 6-8), HMDS (entry 9-11) or bipyNi (COD) (entry 12-14) as the initiator. All polymers were synthesized using THF as the solvent and were characterized by GPC. Mn is the obtained number average molecular weight, $Đ$ is the dispersity index, DP is the obtained degree of polymerization

a bimodal GPC trace was obtained with unexpected low Mn component (Fig. 2e for bimodal GPC trace)

bsignificant amount of NCA was left even after the polymerization reaction continued for 5 days
Table 3 Polypeptides synthesized from LiHMDS-initiated open vessel NCA polymerization

\begin{tabular}{|c|c|c|c|c|c|}
\hline Entry & Polymer & M:I & $\begin{array}{l}\text { Mn } \\
\left(\mathrm{g} \mathrm{mol}^{-1}\right) \\
\end{array}$ & $\boldsymbol{\oplus}$ & DP \\
\hline 1 & poly-BLG & 5 & 6440 & 1.23 & 30 \\
\hline 2 & poly-BLG & 20 & 31,470 & 1.28 & 143 \\
\hline 3 & poly-BLG & 100 & 88,630 & 1.28 & 404 \\
\hline 4 & poly-BLG & 500 & 153,100 & 1.11 & 699 \\
\hline 5 & poly-BLG & 1000 & 283,400 & 1.08 & 1294 \\
\hline 6 & poly-Boc-L-Lys & 5 & 6900 & 1.20 & 30 \\
\hline 7 & poly-Boc-L-Lys & 20 & 13,550 & 1.24 & 59 \\
\hline 8 & poly-Boc-L-Lys & 100 & 62,780 & 1.25 & 275 \\
\hline 9 & poly-Boc-L-Lys & 500 & 111,000 & 1.18 & 486 \\
\hline 10 & poly-Boc-L-Orn & 5 & 6090 & 1.23 & 28 \\
\hline 11 & poly-Boc-L-Orn & 20 & 11,780 & 1.24 & 55 \\
\hline 12 & $\begin{array}{l}\text { poly(Boc-L-Lys)-r-poly } \\
\text { (tBu-L-Ser) }\end{array}$ & 5 & 7200 & 1.24 & 41 \\
\hline 13 & $\begin{array}{l}\text { poly(Boc-L-Orn)- } \\
\text { r-poly(L-Leu) }\end{array}$ & 5 & 6420 & 1.24 & 39 \\
\hline 14 & poly(BLG)-r-poly(tBu-L-Asp) & 5 & 6020 & 1.25 & 35 \\
\hline \multirow[t]{2}{*}{15} & poly-Boc-L-Lys (1st block) & 5 & 6160 & 1.23 & 27 \\
\hline & $\begin{array}{l}\text { poly(Boc-L-Lys)- } \\
b \text {-poly(Boc-L-Lys) }\end{array}$ & & 13,980 & 1.29 & 61 \\
\hline
\end{tabular}


a

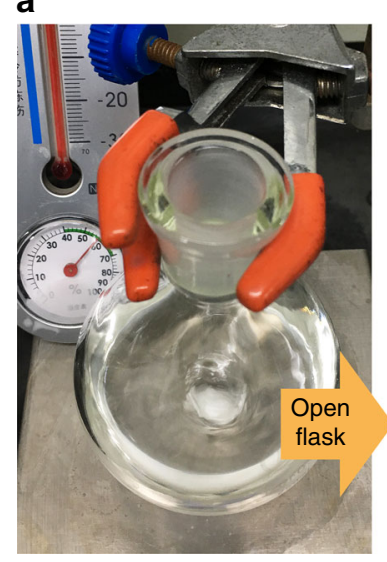

b

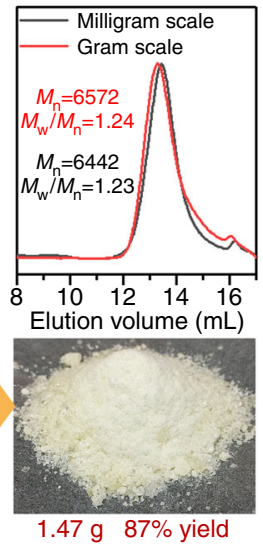

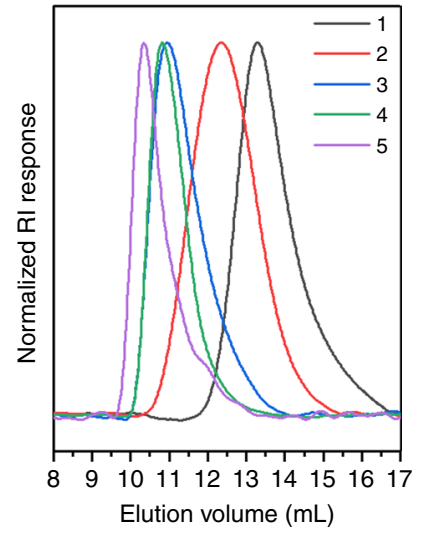

c

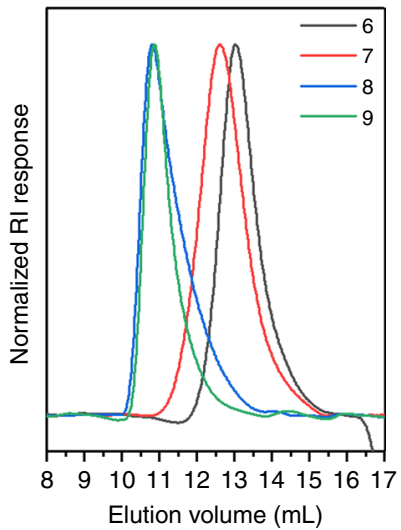

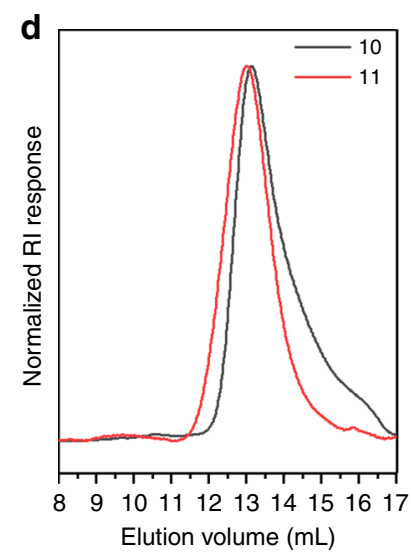
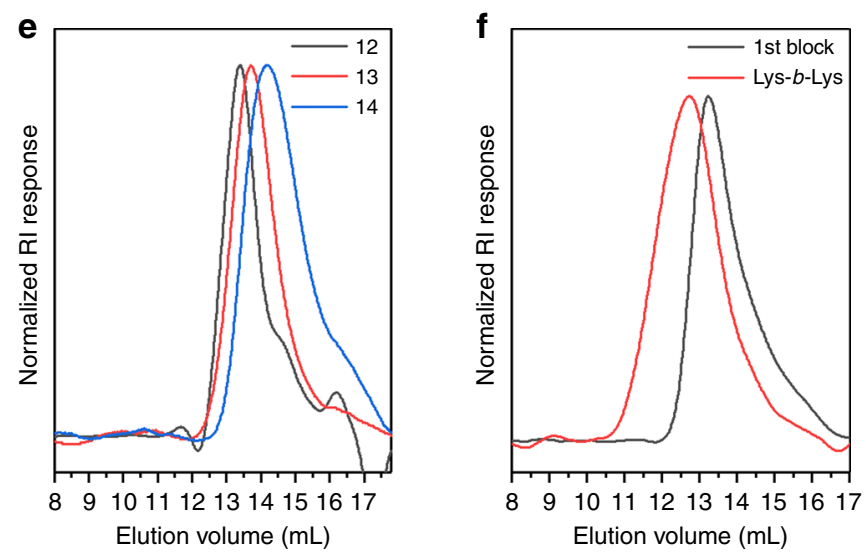

Fig. 3 LiHMDS-initiated open vessel polymerization of various NCAs. a LiHMDS-initiated open vessel polymerization of BLG NCA and corresponding GPC traces of resulting poly-BLG in THF at $26 \mathrm{mg}$ and $2 \mathrm{~g}$ scale, respectively; $\mathbf{b}$ GPC traces of polypeptides polymerized from BLG NCA corresponding to entry 1-5 in Table 3; c GPC traces of polypeptides polymerized from Boc-L-Lys NCA corresponding to entry 6-9 in Table 3; d GPC traces of polypeptides polymerized from Boc-L-Orn NCA corresponding to entry 10-11 in Table 3; e GPC traces of random co-polymers synthesized from a 1:1 mixture of two NCA monomers corresponding to entry 12-14 in Table 3; f GPC traces of the block copolymer corresponding to entry 15 in Table 3. All full scale GPC traces were included in the Supplementary Figs. 75-89

NCA. After a quick completion for the first block $(\mathrm{DP}=27, \mathrm{Ð}=$ 1.23), adding extra Boc-L-Lys NCA to the reaction resulted in successful extension of the polymer to give the final block copolymer ( $\mathrm{DP}=61$ and $\mathrm{D}=1.29$ ) (Table 3, entry 15; Fig. 3f for GPC traces).

Conventional NCA polymerizations are hindered by moisture; therefore, these reactions are generally conducted using a Schlenk line or a glovebox to maintain a dry environment. We were surprised to discover that LiHMDS-initiated BLG NCA polymerization could be performed in an open flask, in an environment with $60 \%$ relative humidity. Polymerizations at milligram scale or gram scale were complete within $5 \mathrm{~min}$ and afforded 30 -mer poly-BLG, in $81 \%$ or $87 \%$ yield, respectively, with narrow dispersities $(\Theta=1.23-1.24)$ as described in Fig. 3a. These findings are important because it is vastly more convenient to conduct NCA polymerizations if a glove box or Schleck line is unnecessary.

Mechanism study on LiHMDS-intiated NCA polymerization. LiHMDS is a non-nucleophilic base, which implies an anionic ring opening polymerization mechanism of LiHMDS-initiated NCA polymerization (Fig. 4a). In the initiation step, LiHMDS may deprotonate either the $3-\mathrm{NH}$ or the $4-\mathrm{CH}$ in a NCA ring. To figure out if the initiation follows one or both pathways, we did FT-IR characterization on a 1:1 mixture of LiHMDS and Boc-D, L-Lys NCA in THF (Fig. 4b, d). In the FT-IR spectrum of Boc-D,
L-Lys NCA, peaks at $1786 \mathrm{~cm}^{-1}$ and $1875 \mathrm{~cm}^{-1}$ represent two carbonyl groups in the NCA ring. In the IR spectrum of 1:1 BocD,L-Lys NCA/LiHMDS mixture, the disappearance of these two peaks indicates the ring opening of NCA; the emergence of peaks at $2231 \mathrm{~cm}^{-1}$ and $1599 \mathrm{~cm}^{-1}$ confirms the formation of isocyanate and carboxylate groups, respectively, in the intermediate 2 (Fig. 4b, d). Above observation, in addition to the lack of IR signal for ketene from 4-CH deprotonation pathway indicates that LiHMDS initiates NCA polymerization by deprotonating the 3-NH rather than the 4-CH in the NCA ring. Further HRESI-MS analysis on the 1:1 Boc-D,L-Lys NCA/LiHMDS mixture found fragments at $\mathrm{m} / \mathrm{z} 279.1532$ and 253.1729 , indicating the transformation of NH-deprotonated Boc-D,L-Lys NCA $\mathbf{1}$ to isocyanate intermediate 2 and a following conversion of the intermediate 2 to free amine fragment 3 (Fig. 4e). In addition, the observation of fragments at $\mathrm{m} / \mathrm{z} 551.3044$ and 525.3112 indicates the formation of dimer 4 and the following conversion of $\mathbf{4}$ to fragment $\mathbf{5}$. During polymerization, once intermediate 4 was formed, the $\mathrm{N}$ terminal lithium carbamate can undergo nucleophile addition to the C5-carbonyl of a new NCA for chain propagation (Fig. 4c). This proposed mechanism for chain propagation was supported by the observation of tripeptide $\mathbf{6}$, having a characteristic Nterminal lithium carbamate group at $m / z 779.4641$ in HRESI-MS (Fig. 4c, e). We hypothesized the N-terminal lithium carbamate in intermediate $\mathbf{4}$, as a weak base, has a low potency to deprotonate $3-\mathrm{NH}$ in a NCA ring and generate an activated NCA that will 
a

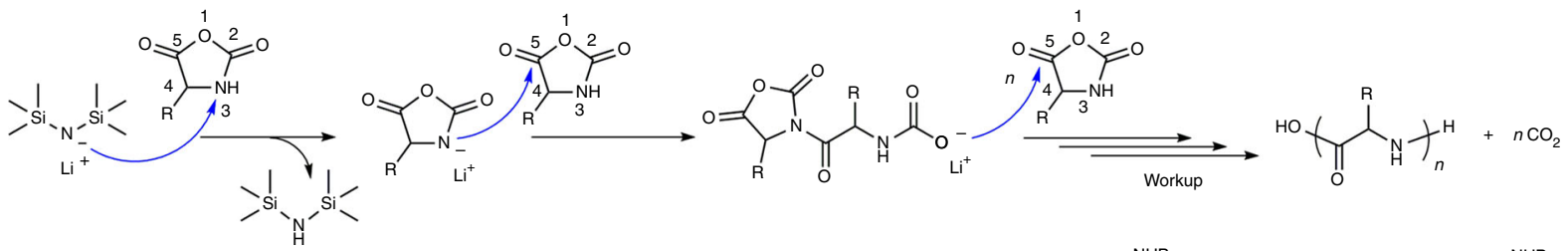

b

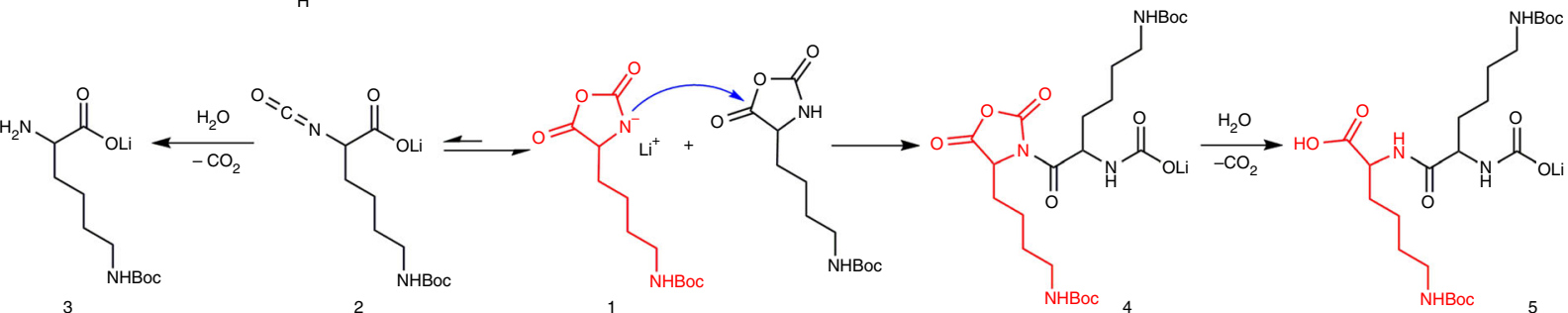

C

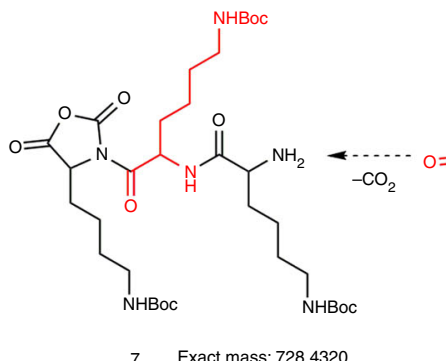

d
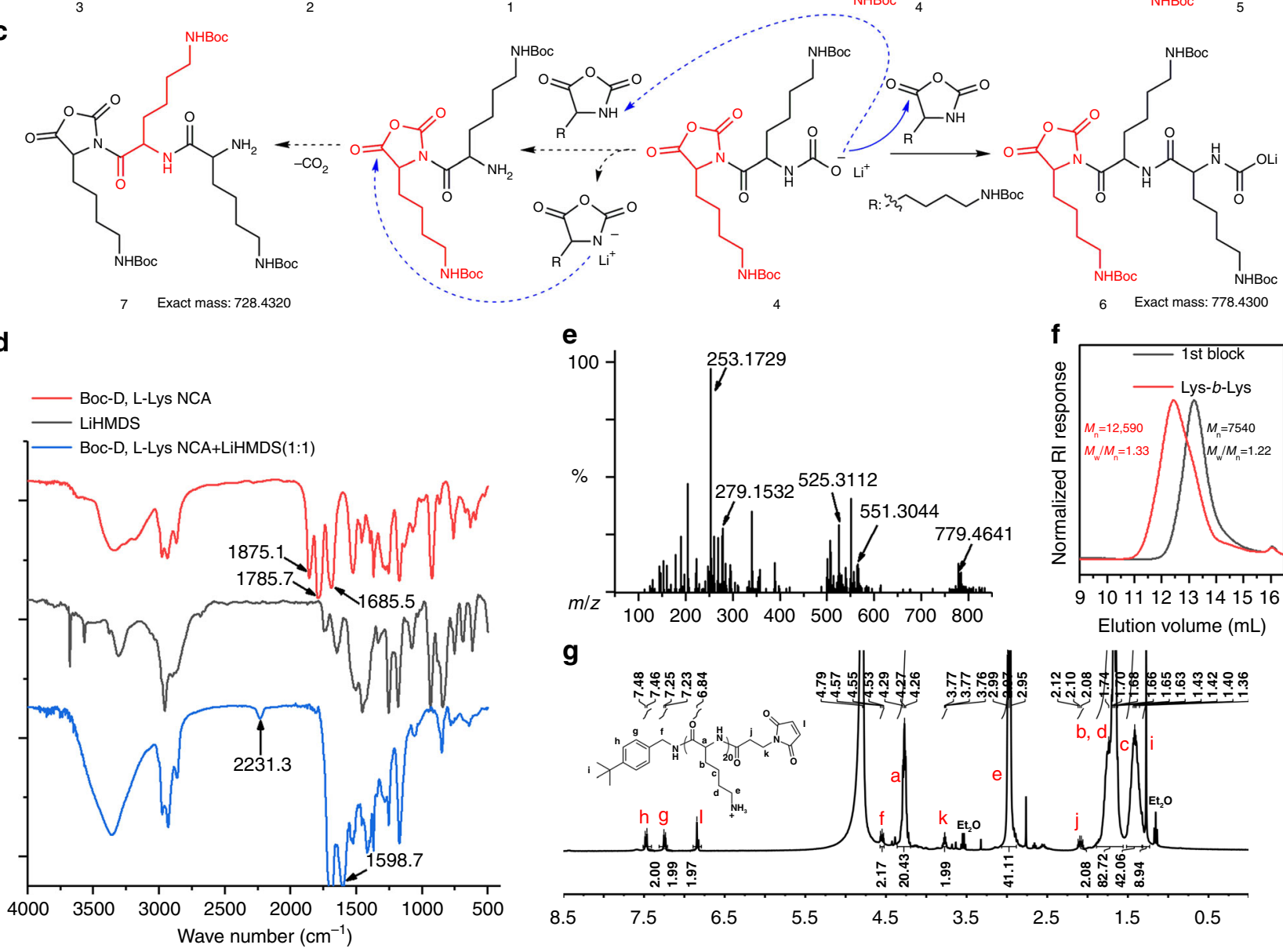

e

e 100

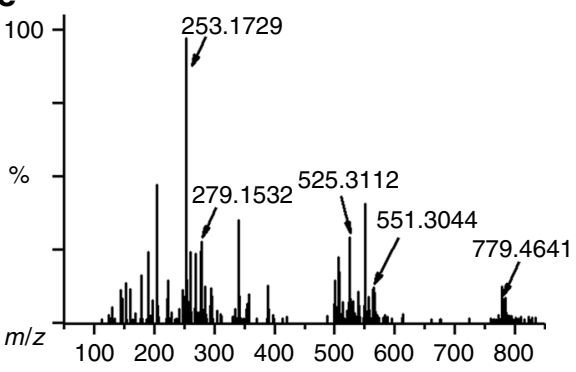

f

6 Exact mass: 778.4300

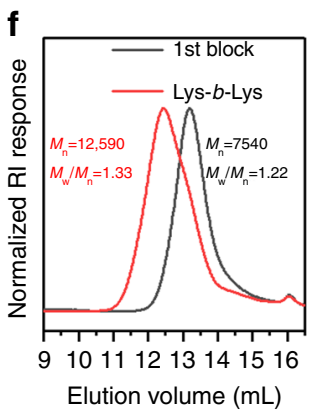

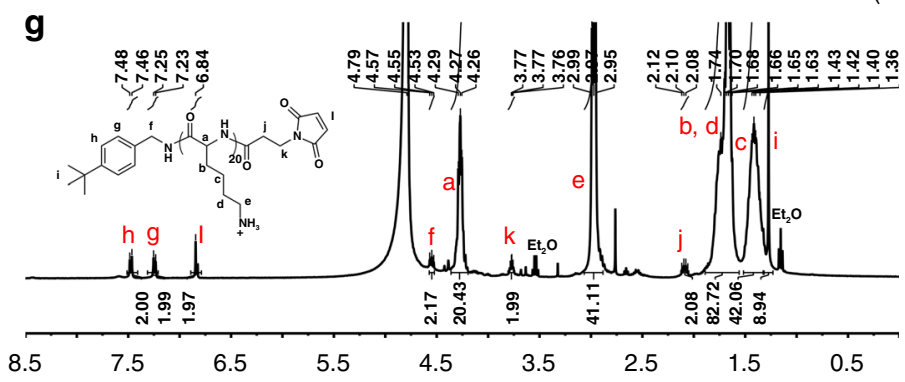

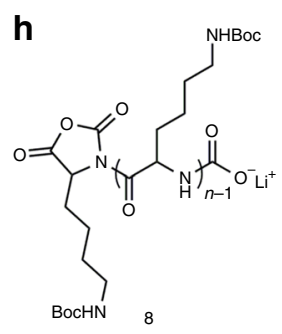<smiles>Cc1ccc(C(C)(C)C)cc1</smiles>

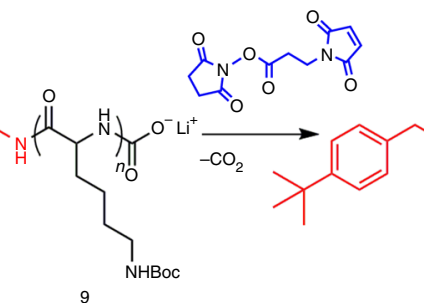<smiles>CNC(=O)C(CCCCNC(=O)[N+](=O)[O-])NC(=O)CCN1C(=O)C=CC1=O</smiles><smiles>CC(C)(C)c1ccc(CNC(=O)C(CCCCN)NC(=O)CCN2C(=O)C=CC2=O)cc1</smiles>

Fig. 4 Mechanism study of LiHMDS-initiated NCA polymerization. a Proposed mechanism of LiHMDS-initiated NCA polymerization; $\mathbf{b}$ transformation of Boc-D,L-Lys NCA in a 1:1 Boc-D,L-Lys NCA/LiHMDS mixture; c comparison between two possible chain propagation pathways; $\mathbf{d}$ FT-IR spectra of Boc-D, LLys NCA, LiHMDS and a 1:1 Boc-D,L-Lys NCA /LiHMDS mixture; e HRESI-MS analysis on a 1:1 Boc-D,L-Lys NCA/LiHMDS mixture; f GPC characterization on block co-polymer of poly(Boc-D,L-Lys)-b-poly(Boc-D,L-Lys) (Lys-b-Lys) obtained from LiHMDS-initiated polymerization of Boc-D,L-Lys NCA. Full scale GPC traces were included in the Supplementary Fig. 73-74. $g$ Proton NMR characterization on terminal functionalization of a 20-mer polypeptide (details see Supplementary Fig. 37) 11; h reaction scheme for N-terminal and C-terminal double functionalization of a 20-mer polypeptide to give polymer $\mathbf{1 1}$, where $n=20$ in the reaction scheme 
result in tripeptide 7 via nucleophilic addition and decarboxylation steps (Fig. 4c). As expected, no signal of tripeptides 7 was found in HRESI-MS spectrum (Fig. 4e). In addition, MALDITOF-MS characterization on purified poly-BLG confirmed the presence of a characteristic $\mathrm{N}$-terminal lithium carbamate group (Supplementary Fig. 7a). These data all support a chain propagation mechanism with $\mathrm{N}$-terminal lithium carbamate as the reactive center ${ }^{68}$. Both FT-IR and HRESI-MS data support an anionic ring-opening polymerization mechanism, where LiHMDS initiates the NCA polymerization by deprotonating 3$\mathrm{NH}$ in the NCA ring for the first step, followed by further nucleophilic addition of N-terminal carboxylate to C5-carbonyl of another NCA (Fig. 4a). A block copolymer, poly(Boc-D,LLys)- $b$-poly(Boc-D,L-Lys), was successfully synthesized by adding the Boc-D,L-Lys NCA into the reaction in two portions sequentially (Fig. 4f). This result indicates a living polymerization property of LiHMDS-initiated NCA polymerization.

Proton NMR characterization on purified poly-BLG obtained a 1:5 ratio for protons in backbone methylene group vs. sidechain benzyl group (Supplementary Fig. 7b). This observation indicates that once the anionic NCA was generated by LiHMDS during the initiation step, it selectively attacked another NCA monomer rather than the side chain benzyl ester because the anhydride carbonyl group is much more reactive than benzyl ester carbonyl group for nucleophilic addition. As the reactive center during polymer chain propagation, the N-terminal carbamate may possibly attacked the C-terminal NCA moiety and form cyclic polypeptides. The resulting cyclic polypeptides were known to be found easily in MALDI-TOF-MS analysis ${ }^{60}$. However, no signal of cyclic polypeptide was found in the MALDI-TOF-MS spectrum of obtained poly-BLG from LiHMDSinitiated polymerization (Supplementary Fig. 7a). We also found no observable cyclization at the end extremity as a possible side reaction during propagation of LiHMDS-initiated BLG NCA polymerization (Supplementary Fig. 38).

According to the proposed mechanism of LiHMDS-initiated NCA polymerization, the resulting polypeptides have a Cterminal NCA group and an N-terminal lithium carbamate group that enable easy functionalization at both ends. We examined this hypothesis using LiHMDS-initiated polymerization of Boc-D,L-Lys NCA as a demonstration to prepared end functionalized poly-Boc-D,L-Lys at 20-mer. To tune the Cterminal end group we added 4-tert-butylbenzylamine, a nucleophile, to the completed polymerization mixture and obtained poly-Boc-D,L-Lys with the expected C-terminal 4-tertbutylbenzyl group (Fig. 4h, polymer 9). To further tune the $\mathrm{N}$ terminal end group we mixed $\mathrm{N}$-succinimidyl 3-maleimidopropionate, an electrophile, with above polymer and obtained polyBoc-D,L-Lys with an N-terminal maleimide group (Fig. 4h, polymer). Proton NMR characterization obtained an integration ratio of 2:2:20 for $\mathrm{H}_{\mathrm{h}}\left(\mathrm{C}\right.$-terminal Benzyl): $\mathrm{H}_{1}(\mathrm{~N}$-terminal maleimide): $\mathrm{H}_{\mathrm{a}}$ (backbone $\left.\mathrm{CH}\right)$, which indicates a successful and controlled terminal functionalization on both ends of this 20 -mer polypeptide to have almost one C-terminal 4-tert-butylbenzyl group and one $\mathrm{N}$-terminal maleimide group per polypeptide chain (Fig. 4g). This result also supports aforementioned statement that acyclic polymers dominate in LiHMDS-initiated NCA polymerization, though we cannot totally rule out the possibility in forming cyclic polypeptides.

Demonstration of LiHMDS-initiated NCA polymerization in polypeptide library synthesis. The LiHMDS-initiated fast NCA polymerization is an excellent fit for rapid synthesis of polypeptide libraries for high-throughput functional screening. We did a proofof-concept demonstration on quick library synthesis of hydrophobic/ cationic amphiphilic co-polymers as mimics of host defense peptide
(HDP) for antibacterial activity screening (Fig. 5). To address the challenge of low stability upon proteolysis, one of the innate and prominent shortcomings of HDP, we used racemic Boc-D,L-Lys NCA rather than homochiral Boc-L-Lys NCA as the cationic subunit within the antimicrobial polypeptides. These amphiphilic copolymers were quickly synthesized from LiHMDS-initiated polymerization using a mixture of BLG NCA and Boc-D,L-Lys NCA. The resulting polypeptides, at about 26-mer, have low dispersities $(\mathrm{Ð}=$ 1.16-1.17) and incrementally increased ratios of the cationic subunit (Fig. 5a, b) (NMR and full GPC traces are shown in Supplementary Figs. 25-36). The large difference in reaction rate between BLG NCA and racemic Boc-D,L-Lys NCA (Fig. 2f) urged us to explore NCA subunit composition of resulting polypeptides. Analyzing on subunit composition within polymer chains along the polymerization progress (or along the NCA conversion) indicated a higher content of BLG than Boc-D,L-Lys at the C-terminus before 30\% consumption of the total NCA monomers. As a consequence, more Boc-D,L-Lys gets into the polymer chain than does BLG at the N-terminal after $80 \%$ consumption of total NCA monomers (Fig. 5c) (see details in Supplementary Methods). It is noteworthy that almost equal ratio of two subunits exists for major part of the polymer in middle of the polymer chain. Although the resulting polymers are not globally random co-polymer, they are still valid as antimicrobial mimics of HDP because our previous study confirmed that some extent of intermixing of two subunits is enough to mimic $\mathrm{HDP}^{54}$. This result also implies that random co-polymers can be prepared in LiHMDSinitiated NCA polymerization if NCA monomers with close reaction rate are used for a combination. The obtained co-polymers from the mixture of BLG NCA and Boc-D,L-Lys NCA were subjected to deprotection and the final polypeptides were evaluated for their activities against multiple bacteria, including Acinetobacter baumannii (A. baumannii), Escherichia coli (E. coli), Bacillus subtilis, (B. subtilis), and multi-drug resistant $P$. aeruginosa and MRSA. A plot of these polypeptides' antibacterial activities, the minimum inhibitory concentrations (MICs), against ratios of subunits within polymers indicates that amphiphilic polypeptides can have strong and broadspectrum antimicrobial activities if having an appropriate subunit ratio, 30-50 molar percentage of the hydrophobic subunit in this study (Fig. 5d). This proof-of-concept demonstration implies that the superfast NCA polymerization developed in this study enables quick library synthesis of polypeptides for high through-put functional screening to find potent and broad-spectrum antimicrobial polypeptides in therapeutic and biomedical applications.

\section{Discussion}

In this study, we report a LiHMDS-initiated superfast NCA polymerization that can afford polypeptides with variable lengths (20-1294 mers) and narrow distributions of molecular weight. Conventional NCA polymerization strategies are highly sensitive to moisture and are generally conducted using a Schlenk line or a glovebox to maintain a dry environment. In sharp contrast, LiHMDS-initiated NCA polymerization can be operated in an open flask outside of the glovebox without any protection. Successful open vessel polymerizations can be achieved under environmental conditions at least in $60 \%$ relative humidity using untreated THF. This method also enables quick library synthesis and large scale synthesis of polypeptides. Moreover, LiHMDS-initiated polymerization can be used for convenient synthesis of long polypeptides. Owing to this NCA polymerization strategy, we quickly synthesized a library of polypeptide and identified polypeptides with broad-spectrum and potent activities against bacteria, including multi-drug resistant $S$. aureus and $P$. aeruginosa. This demonstration validates LiHMDS-initiated NCA polymerization for its capability and potential in combinational chemistry of NCAs to boost the exploration and application of polypeptides in diverse fields. 
a

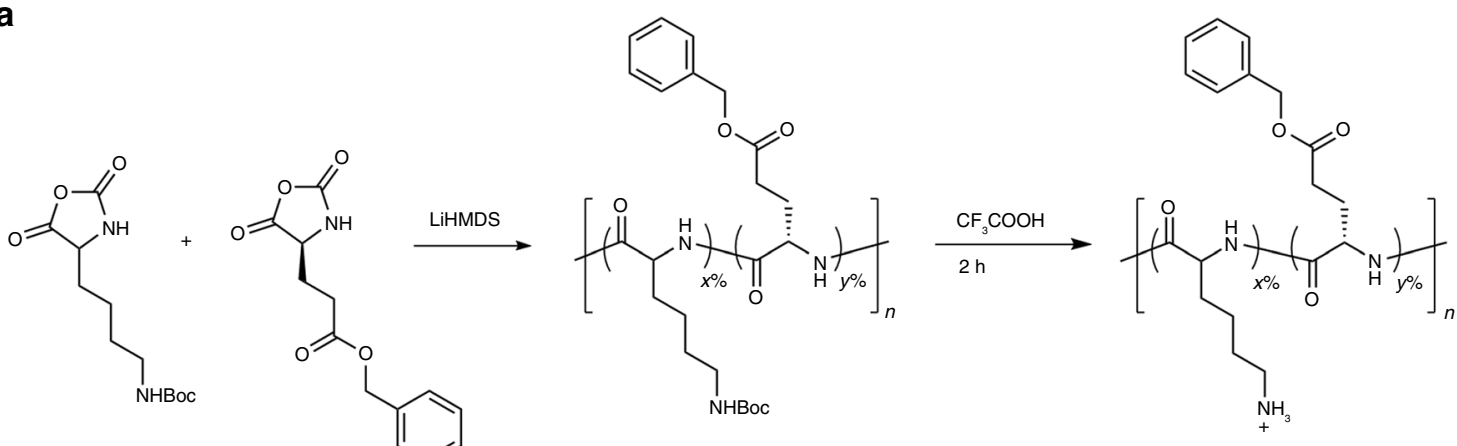

b

\begin{tabular}{cccc}
\hline Boc-D, L-Lys: & \multicolumn{3}{c}{ GPC characterization } \\
BLG $(x: y)$ & $M_{\mathrm{n}}$ & $\oplus$ & $\mathrm{DP}$ \\
\hline $9: 1$ & 6210 & 1.17 & 27 \\
$8: 2$ & 6010 & 1.16 & 26 \\
$7: 3$ & 5880 & 1.16 & 26 \\
$6: 4$ & 5910 & 1.17 & 26 \\
$5: 5$ & 5740 & 1.16 & 26 \\
$4: 6$ & 5600 & 1.16 & 25 \\
\hline
\end{tabular}

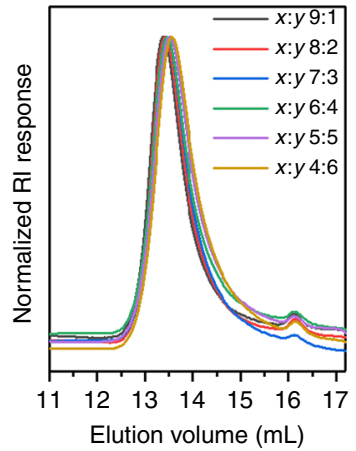

c

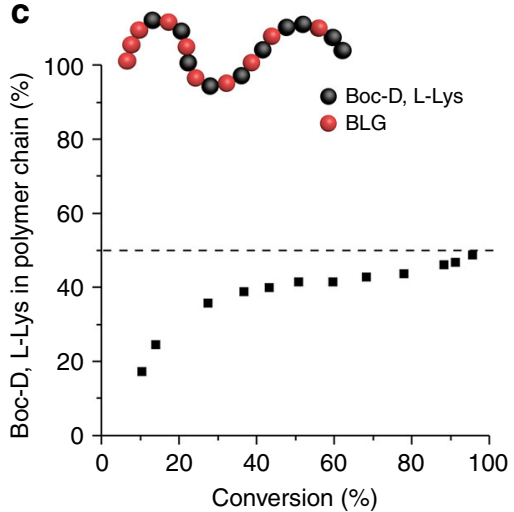

d

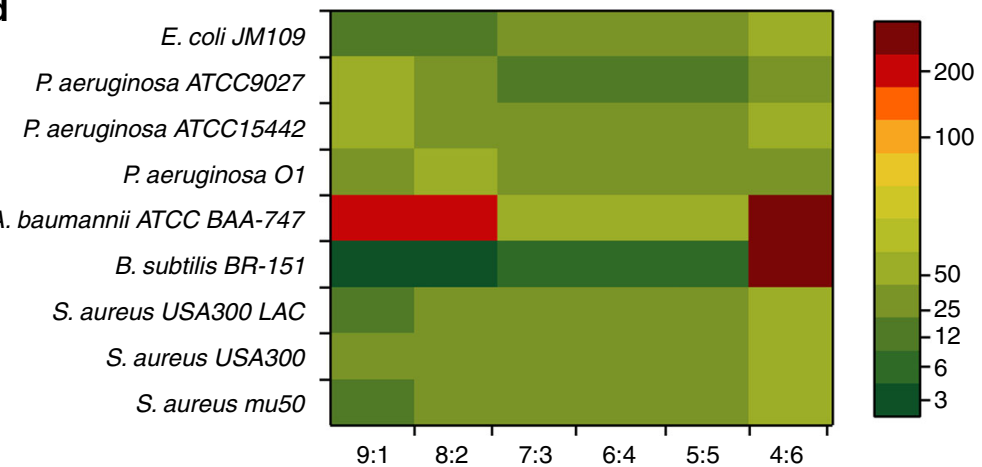

Fig. 5 Fast library synthesis of polypeptides for antibacterial activity studies. a LiHMDS-initiated polymerization of a mixture of BLG NCA and Boc-D,L-Lys NCA in variable NCA ratios, $\mathbf{b}$ characterization and GPC traces of resulting polymers at the NHBoc protected stage. Mn is the obtained number average molecular weight, $\bigoplus$ is the dispersity index, DP is the obtained degree of polymerization; c plot of subunit composition within polymer chains against total NCA conversion; d plot of deprotected polypeptides' antimicrobial activities (MIC) against ratios of subunits ( $x: y$ Boc-D,L-Lys:BLG) within these copolymers, with BLG, the hydrophobic subunit, varied from $10 \%$ to $60 \%$

\section{Methods}

Measurements. ${ }^{1} \mathrm{H}$ NMR and ${ }^{13} \mathrm{C}$ NMR spectra were collected on a Bruker spectrometer at $400 \mathrm{MHz}$ and $100 \mathrm{MHz}$, respectively. ${ }^{1} \mathrm{H}$ NMR chemical shifts were referenced to the resonance for residual protonated solvent $\left(\delta 7.26\right.$ for $\mathrm{CDCl}_{3}, \delta 4.79$ for $\mathrm{D}_{2} \mathrm{O}, \delta 2.50$ for DMSO- $d 6, \delta 1.94$ for $\left.\mathrm{CD}_{3} \mathrm{CN}\right) .{ }^{13} \mathrm{C}$ NMR chemical shifts were referenced to the resonance for residual solvent $\left(\delta 77.16\right.$ for $\mathrm{CDCl}_{3}, \delta 1.32$ for $\left.\mathrm{CD}_{3} \mathrm{CN}\right)$. Gel permeation chromatography (GPC) was performed on a Waters GPC instrument equipped with a Waters 1515 isocratic HPLC pump, a Brookhaven BIMwA multi-angle light scattering detector and a Waters 2414 refractive index detector using DMF supplemented with $0.01 \mathrm{M} \mathrm{LiBr}$ as the mobile phase at a flow rate of $1 \mathrm{~mL} / \mathrm{min}$ at $50^{\circ} \mathrm{C}$. The GPC were equipped by a Tosoh TSKgel Alpha-2500 column (particle size $7 \mu \mathrm{m}$ ) and a Tosoh TSKgel Alpha-3000 column (particle size $7 \mu \mathrm{m}$ ) linked in series. Relative number-average molecular weight $(\mathrm{Mn})$ and dispersity index $(Đ)$ were calculated from a calibration curve using PMMA as standards. Absolute Mn and $Đ$ were calculated using BIC ParSEC Software with a $\mathrm{dn} / \mathrm{dc}$ value of $0.1 \mathrm{~mL} / \mathrm{g}$ for all polymers. Fourier transform infrared (FT-IR) spectra were recorded on a Thermo Electron Nicolet 6700 FT-IR spectrophotometer by using a $\mathrm{KBr}$ plate. High resolution ESI-MS (HRESI-MS) was collected on a Waters XEVO G2 TOF mass spectrometer. High performance liquid chromatography (HPLC) analysis was performed with SHIMADZU LC 20AR HPLC System equipped with a

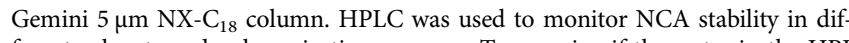
ferent solvents and polymerization progress. To examine if the water in the HPLC eluent have significant effect on the result of analysis during the short time of HPLC elution, the stability studies on NCA in $90 \%$ and $60 \%$ acetonitrile (Supplementary Fig. 3) and the calibration curves (Supplementary Fig. 4) were conducted. Matrixassisted laser desorption ionization time of flight (MALDI-TOF) mass spectra were collected using an AB SCIEX 4800plus MALDI-TOF analyzer in linear mode equipped with a nitrogen laser emitting at $337 \mathrm{~nm}$. 2,5-Dihydroxybenzoic acid (DHB) was used as matrices. Circular Dichroism (CD) was performed with a J-1500 CD Spectrometer (JASCO Corporation) using a temperature-controlled cuvette holder (Quantum Northwest, model TC 125). Chirality of the deprotected polymers at $\lambda=589 \mathrm{~nm}$ was recorded using the Autopol ${ }^{\circledast} \mathrm{V}$ automatic polarimeter at $\mathrm{pH} 8$ and $25^{\circ} \mathrm{C}$. Water content was measured by a Mettler Toledo V20 volumetric KarlFischer titrator. Inductively coupled plasma-mass spectrometry (ICP-MS) samples were run on a PerkinElmer NexION 2000 instrument.

Open vessel NCA polymerization initiated by LiHMDS. To a solution of BLG NCA $(26.3 \mathrm{mg}, 0.1 \mathrm{mmol})$ in THF in a flask open to air at about $60 \%$ relative humidity outside of a glovebox, was added a $0.1 \mathrm{M}$ solution of LiHMDS in THF $(0.2 \mathrm{~mL})$ at room temperature under stirring. The reaction mixture was stirred at 
room temperature for $5 \mathrm{~min}$ and then the resulting polypeptide was precipitated out by pouring the reaction mixture into cold petroleum ether. The precipitation was collected after centrifugation to remove the solvent and dried under vacuum to afford poly-BLG as a white solid $17.7 \mathrm{mg}$ in $81 \%$ yield. Gram scale $(2.01 \mathrm{~g}, 7.63$ mmol) open vessel BLG NCA polymerization was operated by following above operation with reaction stirred at room temperature for $10 \mathrm{~min}$. The purified polyBLG was obtained $1.47 \mathrm{~g}$ in $87 \%$ yield. The operation for open vessel synthesis of poly-BLG in variable chain length was controlled via the BLG NCA:initiator ratio. BLG NCA was weighed out and dissolved in THF to final concentration at $0.1 \mathrm{M}$ to $0.5 \mathrm{M}$, depending on target polypeptide chain length, in an open flask equipped with a magnetic stir bar outside of a glovebox. Then a solution of LiHMDS in THF $(0.02 \mathrm{M}$ or $0.1 \mathrm{M})$ was added to the reaction quickly. The reaction mixture was stirred at room temperature for 5 mins to $2 \mathrm{~h}$ depending on the targeting polypeptide chain length. Poly-BLG 30 was synthesized from a mixture of BLG NCA $(26.3 \mathrm{mg}, 0.1 \mathrm{mmol})$ and a $0.1 \mathrm{M}$ solution of LiHMDS in THF $(0.2 \mathrm{~mL})$ to reach a final BLG NCA concentration at $0.1 \mathrm{M}$. Poly-BLG 143 was synthesized from a mixture of BLG NCA $(26.3 \mathrm{mg}, 0.1 \mathrm{mmol})$ and a $0.1 \mathrm{M}$ solution of LiHMDS in THF $(0.05 \mathrm{~mL})$ to reach a final BLG NCA concentration at $0.1 \mathrm{M}$. Poly-BLG $\mathrm{B}_{404}$ was synthesized from a mixture of BLG NCA $(52.6 \mathrm{mg}, 0.2 \mathrm{mmol})$ and a $0.02 \mathrm{M}$ solution of LiHMDS in THF $(0.1 \mathrm{~mL})$ to reach a final BLG NCA concentration at $0.5 \mathrm{M}$. Poly-BLG $\mathrm{BLo}_{60}$ was synthesized from a mixture of BLG NCA (52.6 mg, 0.2 $\mathrm{mmol})$ and a $0.02 \mathrm{M}$ solution of LiHMDS in THF $(0.02 \mathrm{~mL})$ to reach a final BLG NCA concentration at $0.5 \mathrm{M}$. The poly- $\mathrm{BLG}_{1294}$ was synthesized from a mixture of BLG NCA (105.2 mg, $0.4 \mathrm{mmol})$ and a $0.02 \mathrm{M}$ solution of LiHMDS in THF $(0.02$ $\mathrm{mL}$ ) to reach a final BLG NCA concentration at $1 \mathrm{M}$. Homopolymerization of other NCA monomers (Boc-L-Lys NCA and Boc-L-Orn NCA) were also operated in open vessels using LiHMDS as the initiator by following the protocol of BLG NCA described above. Open vessel synthesis of random co-polymers was performed using the mixture of two NCA monomers (1:1 Boc-L-Lys NCA:tBu-L-Ser NCA, 1:1 Boc-L-Orn NCA:L-Leu NCA, and 1:1 BLG NCA:tBu-L-Asp NCA). Taking one random co-polymerization for example, Boc-L-Lys NCA $(27.2 \mathrm{mg}, 0.1 \mathrm{mmol})$ and $t$ Bu-L-Ser NCA $(18.7 \mathrm{mg}, 0.1 \mathrm{mmol})$ were weighed out and dissolved in THF $(2 \mathrm{~mL})$ in a flask equipped with a magnetic stir bar and open to air. Then a $0.1 \mathrm{M}$ solution of LiHMDS in THF $(0.4 \mathrm{~mL})$ was added to the reaction. The reaction mixture was stirred at room temperature for $5 \mathrm{~min}$ to get complete conversion of the monomers. After diluting the solution to $5 \mathrm{mg} / \mathrm{mL}$ using DMF (containing $0.01 \mathrm{M} \mathrm{LiBr}$ ), the obtained solution was analyzed by GPC to measure the absolute molecular weight (Supplementary Fig. 40). Then the polymer was deprotected to measure the composition using NMR (Supplementary Fig. 39). Random copolymer of poly(Boc-L-Orn $)_{0.5}$-r-poly(L-Leu $)_{0.5}$ was synthesized in an open vessel using the mixture of Boc-L-Orn NCA $(25.8 \mathrm{mg}, 0.1 \mathrm{mmol})$ and L-Leu NCA (15.7 $\mathrm{mg}, 0.1 \mathrm{mmol})$. Random co-polymer of poly(BLG) $)_{0.5}-\mathrm{r}-$ poly $(t \mathrm{Bu} \mathrm{L}-\mathrm{Asp})_{0.5}$ was synthesized in an open vessel using the mixture of BLG NCA $(26.3 \mathrm{mg}, 0.1 \mathrm{mmol})$ and $t \mathrm{Bu}-\mathrm{L}-\mathrm{Asp}$ NCA $(21.5 \mathrm{mg}, 0.1 \mathrm{mmol})$. The open vessel synthesis and characterization of both random co-polymers (Supplementary Figs. 41-44) was performed by following the protocol similar to that of poly(Boc-L-Lys $)_{0.5}-\mathrm{r}$-poly $(t \mathrm{Bu}-$ L-Ser $)_{0.5}$ described above. For the open vessel synthesis of block co-polymer, BocL-Lys NCA $(27.2 \mathrm{mg}, 0.1 \mathrm{mmol})$ was dissolved in THF $(0.7 \mathrm{~mL})$ followed by addition of $0.1 \mathrm{M}$ solution of LiHMDS in THF $(0.2 \mathrm{~mL})$. The reaction was stirred in a flask open to air at room temperature for 2 min to get the first block. Then Boc-LLys NCA $(27.2 \mathrm{mg}, 0.1 \mathrm{mmol})$ in THF $(0.2 \mathrm{~mL})$ was added to the reaction mixture and the reaction was continued for 2 more hours to give the block polymer poly (Boc-L-Lys)- $b$-poly(Boc-L-Lys). These polypeptides were characterized by GPC using DMF as the mobile phase.

\section{Data availability}

Data that support the findings detailed in this study are available in the supplementary information and this article. Any other source data perceived as pertinent are available, on reasonable request, from the corresponding author.

Received: 17 May 2018 Accepted: 16 November 2018

Published online: 13 December 2018

\section{References}

1. Deming, T. J. Synthetic polypeptides for biomedical applications. Prog. Polym. Sci. 32, 858-875 (2007).

2. Zhou, M. N. et al. N-carboxyanhydride polymerization of glycopolypeptides that activate antigen-presenting cells through dectin-1 and dectin-2. Angew. Chem. Int. Ed. 57, 3137-3142 (2018).

3. Checco, J. W. et al. Targeting diverse protein-protein interaction interfaces with alpha/beta-peptides derived from the Z-domain scaffold. Proc. Natl Acad. Sci. 112, 4552-4557 (2015).

4. Kirberger, S. E. et al. Synthesis of intrinsically disordered fluorinated peptides for modular design of high-signal (19) F MRI Agents. Angew. Chem. Int. Ed. 56, 6440-6444 (2017).
5. Xiong, M. et al. Bacteria-assisted activation of antimicrobial polypeptides by a random-coil to helix transition. Angew. Chem. Int. Ed. 56, 10826-10829 (2017).

6. Lee, M. W. et al. Interactions between membranes and "metaphilic" polypeptide architectures with diverse side-chain populations. ACS Nano 11, 2858-2871 (2017).

7. Ong, Z. Y., Wiradharma, N. \& Yang, Y. Y. Strategies employed in the design and optimization of synthetic antimicrobial peptide amphiphiles with enhanced therapeutic potentials. Adv. Drug Deliv. Rev. 78, 28-45 (2014).

8. Mowery, B. P. et al. Mimicry of antimicrobial host-defense peptides by random copolymers. J. Am. Chem. Soc. 129, 15474-15476 (2007).

9. Teng, P. et al. Right-handed helical foldamers consisting of de novo dAApeptides. J. Am. Chem. Soc. 139, 7363-7369 (2017)

10. Li, P. et al. Cationic peptidopolysaccharides show excellent broad-spectrum antimicrobial activities and high selectivity. Adv. Mater. 24, 4130-4137 (2012).

11. Wang, M., Zhou, C., Chen, J., Xiao, Y. \& Du, J. Multifunctional biocompatible and biodegradable folic acid conjugated poly(epsilon-caprolactone)polypeptide copolymer vesicles with excellent antibacterial activities. Bioconjug. Chem. 26, 725-734 (2015).

12. Tang, H. \& Zhang, D. General route toward side-chain-functionalized alphahelical polypeptides. Biomacromolecules 11, 1585-1592 (2010).

13. Gao, Y. F. \& Dong, C. M. Triple redox/temperature responsive diselenidecontaining homopolypeptide micelles and supramolecular hydrogels thereof. Polym. Chem. 56, 1067-1077 (2018).

14. $\mathrm{Wu}, \mathrm{L}$. et al. Intracellular release of doxorubicin from core-crosslinked polypeptide micelles triggered by both $\mathrm{pH}$ and reduction conditions. Biomaterials 34, 5262-5272 (2013).

15. Herce, H. D. et al. Cell-permeable nanobodies for targeted immunolabelling and antigen manipulation in living cells. Nat. Chem. 9, 762-771 (2017).

16. Song, Z. et al. Modulation of polypeptide conformation through donoracceptor transformation of side-chain hydrogen bonding ligands. Nat. Commun. 8, 92 (2017).

17. Hou, Y. et al. Macrocyclization of interferon-poly(alpha-amino acid) conjugates significantly improves the tumor retention, penetration, and antitumor efficacy. J. Am. Chem. Soc. 140, 1170-1178 (2018).

18. $\mathrm{Wu}, \mathrm{X}$. et al. Interleukin-15 and cisplatin co-encapsulated thermosensitive polypeptide hydrogels for combined immuno-chemotherapy. J. Control Release 255, 81-93 (2017)

19. Liu, R., Chen, X., Gellman, S. H. \& Masters, K. S. Nylon-3 polymers that enable selective culture of endothelial cells. J. Am. Chem. Soc. 135, 16296-16299 (2013).

20. Zhou, C. et al. High potency and broad-spectrum antimicrobial peptides synthesized via ring-opening polymerization of alpha-aminoacid-Ncarboxyanhydrides. Biomacromolecules 11, 60-67 (2010).

21. Chen, C., Wang, Z. \& Li, Z. Thermoresponsive polypeptides from pegylated poly-L-glutamates. Biomacromolecules 12, 2859-2863 (2011).

22. Guo, A., Yang, W., Yang, F., Yu, R. \& Wu, Y. Well-defined poly( $\gamma$-benzyl-Lglutamate)-g-polytetrahydrofuran: synthesis, characterization, and properties. Macromolecules 47, 5450-5461 (2014).

23. Liu, H. et al. Reversible thermo-sensitivity induced from varying the hydrogen bonding between the side residues of rationally designed polypeptides. Chem. Commun. 51, 10174-10177 (2015).

24. Zhang, K., Yan, S., Li, G., Cui, L. \& Yin, J. In-situ birth of MSCs multicellular spheroids in poly(L-glutamic acid)/chitosan scaffold for hyaline-like cartilage regeneration. Biomaterials 71, 24-34 (2015).

25. Lai, H. et al. A new strategy to synthesize bottlebrushes with a helical polyglutamate backbone via $\mathrm{N}$-carboxyanhydride polymerization and RAFT. Chem. Commun. 50, 14183-14186 (2014).

26. Leuchs, H. Über die Glycin-carbonsaure. Ber. Dtsch. Chem. Ges. 39, 857-861 (1906).

27. Leuchs, H. \& Manasse, W. Überr die Isomerie der Carbathoxyl-glycylglycinester. Ber. Dtsch. Chem. Ges. 40, 3235-3249 (1907).

28. Leuchs, H. \& Geiger, W. Über die Anhydride von a-Amino-N-carbonsäuren und die von a-Aminosäuren. Ber. Dtsch. Chem. Ges. 41, 1721-1726 (1908).

29. Lu, H. et al. Recent advances in amino acid N-carboxyanhydrides and synthetic polypeptides: chemistry, self-assembly and biological applications. Chem. Commun. 50, 139-155 (2014).

30. Song, Z. et al. Synthetic polypeptides: from polymer design to supramolecular assembly and biomedical application. Chem. Soc. Rev. 46, 6570-6599 (2017).

31. Kricheldorf, H. R. Polypeptides and 100 years of chemistry of alpha-amino acid N-carboxyanhydrides. Angew. Chem. Int. Ed. 45, 5752-5784 (2006).

32. Wibowo, S. H., Sulistio, A., Wong, E. H., Blencowe, A. \& Qiao, G. G. Polypeptide films via N-carboxyanhydride ring-opening polymerization (NCA-ROP): past, present and future. Chem. Commun. 50, 4971-4988 (2014)

33. Deming, T. J. Transition metal-amine initiators for preparation of well-defined poly(gamma-benzyl L-glutamate). J. Am. Chem. Soc. 119, 2759-2760 (1997).

34. Deming, T. J. Facile synthesis of block copolypeptides of defined architecture. Nature 390, 386-389 (1997). 
35. Cheng, J. \& Deming, T. J. Synthesis of polypeptides by ring-opening polymerization of alpha-amino acid N-carboxyanhydrides. Top. Curr. Chem. 310, 1-26 (2012).

36. Lu, H. \& Cheng, J. Hexamethyldisilazane-mediated controlled polymerization of alpha-amino acid N-carboxyanhydrides. J. Am. Chem. Soc. 129, 14114-14115 (2007).

37. Lu, H. \& Cheng, J. N-trimethylsilyl amines for controlled ring-opening polymerization of amino acid $\mathrm{N}$-carboxyanhydrides and facile end group functionalization of polypeptides. J. Am. Chem. Soc. 130, 12562-12563 (2008).

38. Yuan, J., Sun, Y., Wang, J. \& Lu, H. Phenyl trimethylsilyl sulfide-mediated controlled ring-opening polymerization of alpha-amino acid Ncarboxyanhydrides. Biomacromolecules 17, 891-896 (2016).

39. Bhaw-Luximon, A., Jhurry, D., Belleney, J. \& Goury, V. Polymerization of gamma-methylglutamate $\mathrm{N}$-carboxyanhydride using Al-Schiff's base complexes as initiators. Macromolecules 36, 977-982 (2003).

40. Peng, H., Ling, J. \& Shen, Z. Q. Ring opening polymerization of $\alpha$-amino acid $\mathrm{N}$-carboxyanhydrides catalyzed by rare earth catalysts: polymerization characteristics and mechanism. Polym. Chem. 50, 1076-1085 (2012).

41. Dimitrov, I. \& Schlaad, H. Synthesis of nearly monodisperse polystyrenepolypeptide block copolymers via polymerisation of $\mathrm{N}$-carboxyanhydrides. Chem. Commun. 23, 2944-2945 (2003).

42. Vacogne, C. D. \& Schlaad, H. Primary ammonium/tertiary amine-mediated controlled ring opening polymerisation of amino acid $\mathrm{N}$-carboxyanhydrides. Chem. Commun. 51, 15645-15648 (2015).

43. Conejos-Sanchez, I., Duro-Castano, A., Birke, A., Barz, M. \& Vicent, M. J. A controlled and versatile NCA polymerization method for the synthesis of polypeptides. Polym. Chem. 4, 3182-3186 (2013).

44. Zhang, H., Nie, Y., Zhi, X., Du, H. \& Yang, J. Controlled ring-opening polymerization of alpha-amino acid N-carboxy-anhydride by frustrated amine/borane lewis pairs. Chem. Commun. 53, 5155-5158 (2017).

45. Zhao, W., Gnanou, Y. \& Hadjichristidis, N. Organocatalysis by hydrogenbonding: a new approach to controlled/living polymerization of alpha-amino acid N-carboxyanhydrides. Polym. Chem. 6, 6193-6201 (2015).

46. Vayaboury, W., Giani, O., Cottet, H., Deratani, A. \& Schue, F. Living polymerization of alpha-amino acid $\mathrm{N}$-carboxyanhydrides (NCA) upon decreasing the reaction temperature. Macromol. Rapid Commun. 25, 1221-1224 (2004).

47. Habraken, G. J. M., Peeters, M., Dietz, C. H. J. T., Koning, C. E. \& Heise, A. How controlled and versatile is $\mathrm{N}$-carboxy anhydride (NCA) polymerization at $0{ }^{\circ} \mathrm{C}$ ? Effect of temperature on homo-, block- and graft (co)polymerization. Polym. Chem. 1, 514-524 (2010)

48. Aliferis, T., Iatrou, H. \& Hadjichristidis, N. Living polypeptides. Biomacromolecules 5, 1653-1656 (2004).

49. Habraken, G. J. M., Wilsens, K. H. R. M., Koning, C. E. \& Heise, A. Optimization of N-carboxyanhydride (NCA) polymerization by variation of reaction temperature and pressure. Polym. Chem. 2, 1322-1330 (2011).

50. Pickel, D. L., Politakos, N., Avgeropoulos, A. \& Messman, J. M. A mechanistic study of alpha-(amino acid)-N-carboxyanhydride polymerization: comparing initiation and termination events in high-vacuum and traditional polymerization techniques. Macromolecules 42, 7781-7788 (2009).

51. Zou, J. et al. A facile glovebox-free strategy to significantly accelerate the syntheses of well-defined polypeptides by N-carboxyanhydride (NCA) ring opening polymerizations. Macromolecules 46, 4223-4226 (2013).

52. Zhang, J., Kissounko, D. A., Lee, S. E., Gellman, S. H. \& Stahl, S. S. Access to poly-beta-peptides with functionalized side chains and end groups via controlled ring-opening polymerization of beta-lactams. J. Am. Chem. Soc. 131, 1589-1597 (2009)

53. Zhang, J. et al. C-terminal functionalization of nylon-3 polymers: effects of Cterminal groups on antibacterial and hemolytic activities. Biomacromolecules 13, 323-331 (2012).

54. Liu, R. et al. Tuning the biological activity profile of antibacterial polymers via subunit substitution pattern. J. Am. Chem. Soc. 136, 4410-4418 (2014).

55. Liu, R. et al. Nylon-3 polymers active against drug-resistant Candida albicans biofilms. J. Am. Chem. Soc. 137, 2183-2186 (2015)

56. Liu, R. et al. Structure-activity relationships among antifungal nylon-3 polymers: identification of materials active against drug-resistant strains of Candida albicans. J. Am. Chem. Soc. 136, 4333-4342 (2014).

57. Liu, R., Masters, K. S. \& Gellman, S. H. Polymer chain length effects on fibroblast attachment on nylon-3-modified surfaces. Biomacromolecules 13, 1100-1105 (2012).

58. Liu, R., Suarez, J. M., Weisblum, B., Gellman, S. H. \& McBride, S. M. Synthetic polymers active against Clostridium difficile vegetative cell growth and spore outgrowth. J. Am. Chem. Soc. 136, 14498-14504 (2014).

59. Liu, R. et al. Nylon-3 polymers with selective antifungal activity. J. Am. Chem. Soc. 135, 5270-5273 (2013).

60. Kricheldorf, H. R., Von Lossow, C. \& Schwarz, G. Cyclic polypeptides by solvent-induced polymerizations of alpha-amino acid N-carboxyanhydrides. Macromolecules 38, 5513-5518 (2005).
61. Kricheldorf, H. R., Von Lossow, C. \& Schwarz, G. Primary amine and solventinduced polymerizations of L- or D,L-phenylalanine N-carboxyanhydride. Macromol. Chem. Phys. 206, 282-290 (2005).

62. Kramer, J. R. \& Deming, T. J. General method for purification of alpha-amino acid-N-carboxyanhydrides using flash chromatography. Biomacromolecules 11, 3668-3672 (2010).

63. Peng, Z. H. et al. Synthesis of filibuvir. Part II. Second-generation synthesis of a 6,6-disubstituted $2 \mathrm{H}$-pyranone via dieckmann cyclization of a beta-acetoxy ester. Org. Process Res. Dev. 18, 36-44 (2014).

64. Bonduelle, C. Secondary structures of synthetic polypeptide polymers. Polym. Chem. 9, 1517-1529 (2018).

65. Doty, P., Wada, A., Yang, J. T. \& Blout, E. Polypeptides. VIII. Molecular configurations of poly-L-glutamic acid in water-dioxane solution. J. Polym. Sci. 23, 851-861 (1957)

66. Huesmann, D. et al. Revisiting secondary structures in NCA polymerization: influences on the analysis of protected polylysines. Macromolecules 47 , 928-936 (2014)

67. Pranantyo, D., Xu, L. Q., Hou, Z., Kang, E. T. \& Chan-Park, M. B. Increasing bacterial affinity and cytocompatibility with four-arm star glycopolymers and antimicrobial alpha-polylysine. Polym. Chem. 8, 3364-3373 (2017).

68. Giannakidis, D. \& Harwood, H. J. Detection of initiator fragments in polyvalines and polyleucines derived from carbamate salt-initiated polymerizations of N-carboxy anhydride. J. Polym. Sci. 16, 491-496 (1978).

\section{Acknowledgements}

This research was supported by the National Natural Science Foundation of China for Innovative Research Groups (No. 51621002), the National Natural Science Foundation of China (No. 21574038, 21774031), the National Key Research and Development Program of China (2016YFC1100401), the "Eastern Scholar Professorship" from Shanghai local government (TP2014034), the 1000 talent young scholar program in China, 111 project (B14018), the national special fund for State Key Laboratory of Bioreactor Engineering (2060204), the Fundamental Research Funds for the Central Universities (22221818014), the program for professor of special appointment at ECUST. The authors also thank Research Center of Analysis and Test of East China University of Science and Technology for the help on the characterization. The authors thank Professor Samuel H. Gellman for invaluable discussions on the manuscript.

\section{Author contributions}

Y.W. and R.L. conceived the idea, proposed the strategy, designed the experiments, evaluated the data, and wrote the manuscript together. Y.W. performed majority of the experiments. D.Z. participated NCA synthesis and initial polymerization test. P.M conducted the antimicrobial assay. R.Z. participated HPLC analysis. L.H. participated MassSpec spectra analysis. All authors proof read the manuscript.

\section{Additional information}

Supplementary Information accompanies this paper at https://doi.org/10.1038/s41467 018-07711-y.

Competing interests: R.L. and Y.W. are co-inventors on a patent covering reported NCA ring opening polymerization. All remaining authors declare no competing interests.

Reprints and permission information is available online at http://npg.nature.com/ reprintsandpermissions/

Publisher's note: Springer Nature remains neutral with regard to jurisdictional claims in published maps and institutional affiliations.

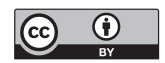

Open Access This article is licensed under a Creative Commons Attribution 4.0 International License, which permits use, sharing, adaptation, distribution and reproduction in any medium or format, as long as you give appropriate credit to the original author(s) and the source, provide a link to the Creative Commons license, and indicate if changes were made. The images or other third party material in this article are included in the article's Creative Commons license, unless indicated otherwise in a credit line to the material. If material is not included in the article's Creative Commons license and your intended use is not permitted by statutory regulation or exceeds the permitted use, you will need to obtain permission directly from the copyright holder. To view a copy of this license, visit http://creativecommons.org/ licenses/by/4.0/.

(C) The Author(s) 2018 